\title{
Re-use of the industrial heritage of Bovisa: a model for urban and cultural regeneration
}

\author{
A. Villacampa ${ }^{1} \&$ Y. Villacampa ${ }^{2}$ \\ ${ }^{1}$ Politecnico di Milano. Italy \\ ${ }^{2}$ Departamento Matemática Aplicada, Universidad de Alicante, Spain
}

\begin{abstract}
After the deindustrialization process of Europe many buildings and complexes were abandoned and their activities were moved out of the cities due to the growth of urban centres. One of those locations is Bovisa in the North of Milan, where old structures of former factories are standing near contemporary buildings. Furthermore, as a common characteristic of old industrial urban areas, the price of land is one of the factors that affect industrial archaeology preservation and its future development. The main goal of this research is to develop a gentrification strategy that can be sustainable for the urban growth and social development of the area. Based on this, the analysis will be presented within two considerations: 1) the adaptive re-use of these buildings has been considered as a motor for sustainability and culture in Bovisa. 2) There has been developed a mathematical model based on a multivariate analysis of the global quantification of factors that take part in the process. This approach has led to the planning and classification of the area followed by a multivariate analysis and a regression model generation. This methodology classifies the area according to the cultural planning development and the recoverability of green areas. A multivariate analysis of the 27 sectors in which Bovisa can be divided has been undertaken. The generation of regression models will help us define the factors that contribute the most to the cultural and greenery recovery. However, a factorial analysis has been made on the data matrix obtained through the quantification of the variables that affect a possible gentrification. This will define the "cultural recovery" and "greenery recovery" indexes and the classification of the sectors in homogeneous zones according to a sustainable gentrification process.
\end{abstract}

Keywords: deindustrialization, urban sustainability, gentrification, industrial heritage, cultural development, mathematical model. 


\section{Introduction}

Since the end of the 1980s, an important process of urban re-generation has taken place in the Milano-Bovisa area. In this transformation, Politecnico di Milano is still one of the main actors contributing to the development of the area with two campuses for architecture, engineering and design. The whole development was not a single project but a conjunction of progressive phases, which has not yet been completed. The Bovisa district is an ex-industrial area, in the Northwest outskirts of Milan (Italy), where only a few houses where located until 1880. The development of Bovisa began when several chemistry companies sited their factories in the area transforming it into one of the main hubs of the Italian industrial chemistry sector. At the beginning of the 1900s, the workshops and warehouses of Teatro alla Scala also established there for set design and costume production. The setting up of the regional railway company (Ferrovie Nord) became an asset for the development of electromechanical industries as well. This way, the factories of Bovisa reached a national production stage. Nevertheless, since the 1970s, the industrial re-conversion process has started and numerous factories have been closed. Between 1974 and 1985, industrial workers in the Milanese factories decreased from 12,000 to 6,000. However, it was during these years when the idea of a new Politecnico campus in Bovisa emerged to be officialised by the Milan Municipality in 1987.

The good connections with Malpensa Airport, main train stations, city centre and the new Fairground Exhibitions area enforced the position and role of Bovisa as one of the strategic areas of Milan. Politecnico di Milano officially opened a campus in Bovisa in 1989, at the ex-FBM industrial hangar. In 1994 the plants of ex-Ceretti \& Tafani (cable way production) at via Durando were renovated to host the Faculties of Architecture and Design. Nowadays, the campuses are well integrated in the neighbourhood where about 6,500 students and 300 employees work every day [1]. Within the precedent context, the development of a gentrification strategy that can be sustainable for the urban, cultural and social growth of the area comes out supported by a mathematical model: a tool based on a multivariate analysis of the diverse main factors of Bovisa. For this analysis there has been evaluated a whole - but not closed database that measures variables such as the amount of industrial buildings and their state of conservation; the existing and possible future green areas; the soil pollution levels for each former industry location according to the kind of activity developed; the location itself and the actual use, among others. The subdivision of the area in sectors (each sector corresponds to a street called via in Italian) responds to a classification and characterization requirement of all the variables for each building and the comparison of each single factor. Since this mathematical model aims to be a tool for the re-generation of an urban area, it can be enriched with the computation of new external factors such as financial investments and costs, public transport development and so. In this way, the model will grow and increase the chances to generate a sustainable urban planning strategy starting from the most favourable building, location or street according to the factors previously computed for each case study. 


\section{Reuse and sustainable gentrification}

The city of Milan, like most western cities, has gone through important economic, social and cultural changes. The great industrial zones that surrounded the urban areas up to the end of the 20th century, with small and medium sized companies that complemented their production, had faced the repercussion of technological progress and market needs and have moved to other locations. Consequently, the areas that have been freed from this type of use are nowadays placed in semi-central parts of the city, generally close to the public transport network. In this new context, the economy of Milan is still based on business sectors like fashion, chemical production or industrial design. Moreover, the presence of different ethnic groups in the city that have settled in the suburban context generates the need to face cultural changes. In Milan, the structure of the cultural and artistic production at an international level offers many opportunities provided by new entrepreneurs focused on young and contemporary artists. These business operators often work in associations or as truly independent entrepreneurs. They have always welcomed the strong potential of young people's ideas without however giving form to these experiences thanks to the creation of an official cultural network. In the context of a cultural re-use, there exist several companies in Milan that develop cultural projects at different levels with similar characteristics: La Fabbrica del Vapore, Fondazione Arnaldo Pomodoro, The HUB, Lambretto Art Project or Assab One among others. All these examples are located in buildings originated by industrial uses that have been adapted to a cultural program. Moreover, in the area of Bovisa there are other remarkable cultural and educational institutions like Politecnico di Milano and Triennale Bovisa. In addition, the ongoing master plan by Euromilano called Nuova Bovisa will impulse the educational and business activities on the area. This situation can be seen as an asset for urban change and for the sustainable development of a derelict area in Milan. It is a fact that the ongoing projects of the whole sector of Bovisa will regenerate a post-industrial suburb into a remarkable cultural and educational site in town since the area has become an important location for university and other cultural institutions. The population of the Bovisa neighbourhood nowadays varies from students and artists to traditional inhabitants and immigrants who share their everyday life in an industrial context where the price and the use of the land is in constant change due to the state of urban re-design processes required by the municipality and other investors. At the same time, the population of Bovisa moves constantly depending on the day of the week, the time of the day or the events and exhibitions that are temporary shown at the crafts and art galleries. However, new green areas, the improvement of the public transport system and the construction of a science park are some future considerations that will condition the sustainable gentrification process of the whole neighbourhood.

The development of Milan is an ongoing process that will transform its industrial outskirts and that will integrate them in the urban area. The inhabitants of the neighbourhood will enjoy better train, metro, bus and tram connections as part of the transformation process of the city. 


\section{Goals and tools}

However the development of Bovisa is based on urban planning and architecture principles, the gentrification has to be intended as a cultural planning strategy that requires close interaction with the given context starting with the geography, demography and social history. Furthering the research, a closer investigation is devoted to what issues are relevant to the place and can be tackled through contemporary cultural actions. At this point, education becomes a built-in part of the concept and community groups are invited to contribute to the project. In terms of marketing, the mechanisms for reaching different groups, in the immediate surroundings and further afield have to be put in place. Then, the analysis practice has to be done by looking closely at all the underneath elements of each cultural planning project [2]. In this article, the preservation of the identity of a city and the creation of one of the largest cultural networks in Europe are the vision of the project. In addition, the urban and social development of a derelict area has to be considered as the mission of the proposal. We must point that this kind of approach is unique since multivariate models have not been previously used as a tool for cultural planning and urban development. Nowadays, cultural initiatives and new activities in Bovisa come and go because there is no solid network to support them and investors do not give a value to the industrial identity of the town. Due to this, the main goal of the research is to introduce new methodologies that can analyze, classify and plan the recovery of the neighbourhood protecting its industrial legacy. We present the generation of mathematical models based on a multivariate analysis as a valid method for urban and cultural planning: regression models, factorial analysis and cluster analysis define and evaluate a sustainable gentrification process. Further investigations following the same methodology will add new factors to obtain new classifications to compare each zone according to the kind of factors chosen for each situation or requirement.

\section{Modeling for cultural recovery and green areas}

In the area of Bovisa, 27 zones or sectors have been defined corresponding to 27 streets (via in Italian) in which several industrial activities settled down many years ago. All the sectors have been analyzed and compared among them from the cultural re-use and recovery of the green areas perspective (parks, gardens, urban orchards). To reach this goal, we will initially quantify - for each sector the factors that directly affect the social and cultural regeneration (sustainable gentrification). With the evaluated database we will determine a multivariate analysis that will give us a relation between the variables and the generation of multiple regression models. Those models will determine mathematical equations to analyse relationships and to simulate situations. Furthermore, the factorial analysis of the components has let us to define indexes and gentrification indicators as well as a classification of the zones to establish an order linked to the possibilities of cultural and green area recovery. 


\subsection{Analysis of variables that influence a sustainable gentrification}

Fourteen variables have been defined to obtain a real numeric database for each one of the 27 sectors; in other words, a numeric value has been given to each sector in a previously established scale for each case. The defined variables are: $\mathrm{X} 1$ : industrial buildings (in use); X2: industrial buildings (abandoned); X3: new buildings (non-residential use); X4: Total Floor Area in Use (TFAUS); X5: Total Floor Area Abandoned (TFAAB); X6: Total Floor Area (TFA); X7: Total Floor Area Empty (TFAEM); X8: Green area: spontaneous; X9: Green area: park (public or private); X10: soil pollution that can vary from 1 (non polluted) to 10 (highly polluted); X11: Environmental Sustainability Index (ESI) with values from 1 (unsustainable) to 10 (very sustainable); X12: Environmental Recovery Index (ERI) with values from 1 (low recovery) to 3 (high recovery); $\mathrm{X} 13$ : cultural regeneration ability that can vary from 1 to 10 ; X14: possible recovery of green areas: urban orchards and gardens (from 1 to 10). The analysis of the binary correlations indicates the variables correlated more with the cultural recovery and the green areas recovery, as well as the possible existing collinearity between the variables. After this we can affirm that there exists collinearity between X8 and X5. Moreover, the variable X13 correlated more with the variables X2, X5, X8, X10, X11, X12 and X14 but correlated less with X3, X6 and X7. The variable "regeneration of green areas" (X14) has a higher correlation with X10, X11, X12 and X13, being significantly less related with $\mathrm{X} 3, \mathrm{X} 6$ and X8.

\subsection{Regression models}

For this article, we have used the regression models to analyze the possible regeneration of cultural and green areas in Bovisa. Due to this, some mathematical equations to link the variables have been determined. Indeed, it is possible to start determining one model with all the variables, 1 dependent and 13 independent, and then go on through an elimination of variables. Then, we must apply model selection criteria to determine the simplest model in order for us to study the dependent variables [3, 4]. Furthermore, if we consider the correlation analysis between variables, we can begin our study of the modes eliminating $\mathrm{X} 1, \mathrm{X} 2$ and $\mathrm{X} 3$ from them. Moreover, due to the collinearity between the variables $\mathrm{X} 5$ and $\mathrm{X} 8$, the two variables will not appear in the obtained models. The multiple lineal regression models have been analyzed with the computational software SPSS [5] and SPLUS [6]. Moreover, we have made a change of the variable to be able to use standardized variables $\left\{z_{i}\right\}_{i}$. To determine a selection of the regression models the backward stepwise selection $[3,4]$ has been applied.

\subsection{Cultural recovery models}

The variable $z_{13}$ represents the "cultural recovery"; its relation with other variables has been determined through regression models. Starting from a model 
where all the possible independent variables take part, the backward stepwise selection method selects the best models. Seven models have been obtained from which we will choose the simplest one through determining the \% among the explained data. This is defined through the value of the regression coefficient R2 multiplied by 100 .

$$
\begin{gathered}
z_{13}=4,153 E-6+0,421 \mathrm{z}_{4}+0,655 \mathrm{z}_{8}-0,263 \mathrm{z}_{12} \cong 0,421 \mathrm{z}_{4}+0,655 \mathrm{z}_{8}-0,263 \mathrm{z}_{12} \\
R^{2}=0,844
\end{gathered}
$$

The model explains $84 \%$ of the experimental data. In this way, we can study the possible cultural regeneration of the area from an analysis of the variables: total floor area, green area "spontaneous" and recovery index (ESI).

\subsection{Models for recoverability of green areas}

In the same way as for variable $z_{14}$ (recovery of green areas) we studied families of lineal models to obtain eight models. Among these, we have selected the simplest one determining the $\%$ of the database defined as the value of the regression coefficient $\mathrm{R}^{2}$ multiplied by 100 :

$$
z_{14}=-2,285 E-6-0,170 \mathrm{z}_{6}-0,912 \mathrm{z}_{10} \cong-0,170 \mathrm{z}_{6}-0,912 \mathrm{z}_{10} ; \quad R^{2} \cong 0,89
$$

The model explains $89 \%$ of the experimental data. It is possible then to study the recoverability of green areas analyzing the variables: "Total Floor Area (TFA)" and "soil pollution".

\subsection{Cultural recovery index and green areas}

When studying a determined process or its variables from the characteristics that influence it (the variables are measured in different units), it is normal to assign a weighing to each variable according to the information that it gives us. The multivariable technique used for this procedure consists of making - on the matrix of the data - a factorial analysis to try to define factors that can explain the configuration of the correlations inside the same set of the observed variables. This is a way of reducing the information of the data into factorial numbers that explain the majority of the variances that we have observed. There exist many methods to define the factors. Even if it is normal to apply the technique to reduce the dimension of the matrix of the data, it is possible to use those factors to define indexes as well. Please note that this method has already been applied in some previous studies [7, 8]. In this article, an analysis of the main components or "method for the determination of factors" to form independent lineal combinations of the variables has been used. Here, the factors are non-dimensional since it is made with the standardized variables and they are not correlated two by two. The first factor accumulates the higher percentile of variance or total information followed by the others until the definition of the indexes of the latest factors which barely accumulate information. This propriety allows the definition of indexes from the factors as far as the proportion of information that they can explain weights them. The factorial analysis applying 
the backward stepwise selection method gives us a total of four factors. They explain nearly $84 \%$ of the variability in the original fourteen variables. In this way, we can reduce considerably the complexity of the dataset by using these components with only a $16 \%$ loss of information. The factorial matrix (components matrix) indicates the correlations of the factors with the variables representing the weight that each variable assigns to the factor. The first component is most highly correlated with $z_{10}, z_{11}, z_{12}, z_{13}$ and $z_{14}$. The variable $z_{12}$ is a better representative however because it is correlated less with the other three components. The index defined from the first main component will be representative for a possible sustainable gentrification. The second component is most highly correlated with $z_{1}, z_{2}, z_{5}$ and $z_{8}$. The variables $z_{2}$, $z_{5}$ and $z_{8}$ are better representative however because they are correlated less with the other two components; the third component is most highly correlated with $z_{1}$ and the fourth one is most highly correlated with $z_{3}$ and $z_{6}$.

\subsection{Index based on the first component.}

From the factorial matrix (components matrix) and from the first main component we can define the index 1 of the gentrification as:

$$
I N D G_{1}=\sum_{i=1}^{14} a_{i 1} z_{i}
$$

In the study made for the 27 sectors of Bovisa, the index has been defined through the following equation:

$$
\begin{aligned}
& I N D G_{1}=0,021 Z_{1}+0,04 Z_{2}+0,043 Z_{3}+0,044 Z_{4}+0,067 Z_{5}+0,023 Z_{6}-0,282 Z_{7}+0,067 Z_{8}+ \\
& +0,133 Z_{9}-0,258 Z_{10}+0,242 Z_{11}+0,201 Z_{12}+0,047 Z_{13}+0,244 Z_{14}
\end{aligned}
$$

The values for each zone give us positive and negative values. We can make a transformation defined by the function $F\left(I N D G_{1}\right)$ that transforms these values into positive numbers establishing a classification of the zones according to its possible gentrification ability. Here the authors will apply the transformation proposed by Calsamiglia [9] for the values located on the interval $[0,100]$. To do this it is enough to apply the function defined for the values of $I N D G_{1}$ :

$$
\text { if } I N D G_{1}<0, F\left(I N D G_{1}\right)=1+(99 / 2) e^{I N D G_{1}} ; \text { if } I N D G_{1} \geq 0 F\left(I N D G_{1}\right)=100-(99 / 2) e^{-I N D G_{1}}
$$

The classification of the zones and the order from minor to major ability of gentrification can be seen in figure 1 . 


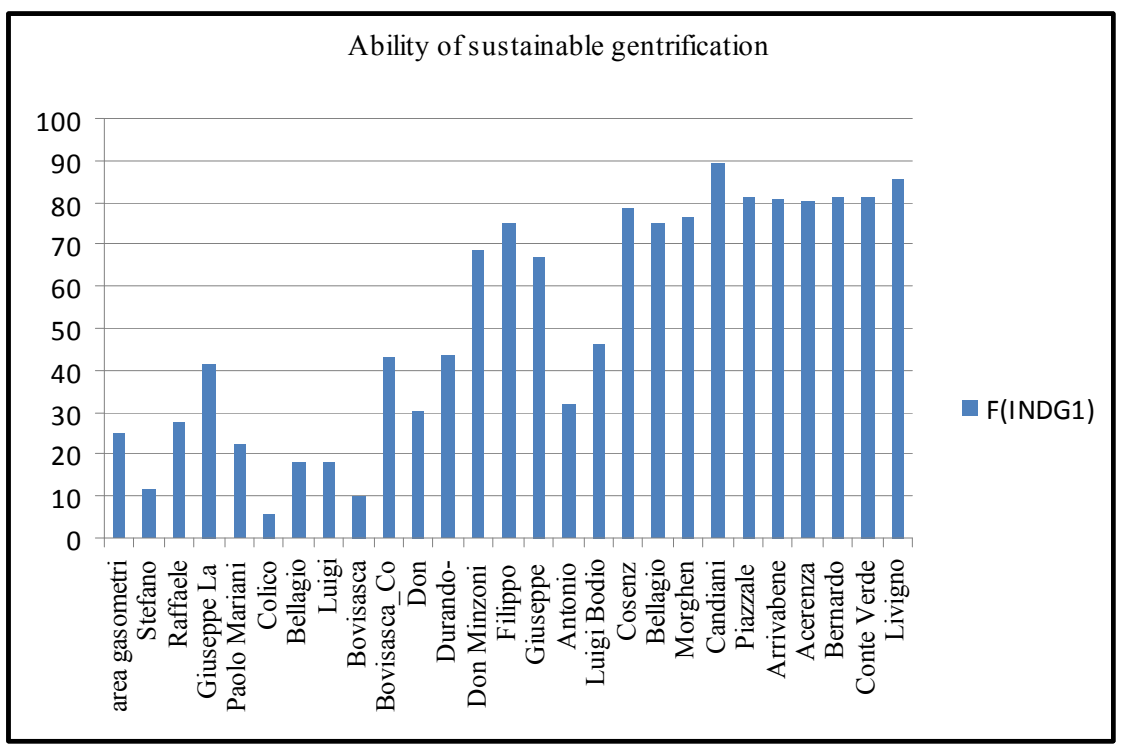

Figure 1: $\quad$ Index of gentrification ability.

\subsection{Classification in homogeneous zones according to a sustainable gentrification process}

The factors obtained during the factorial analysis have been taken as four new variables. This will let us apply a cluster analysis or conglomerate analysis to the 27 areas linked to the factors that classify the zones as homogeneous due to their belonging to the same cluster/conglomerate. First, we will obtain a classification from the belonging to each cluster/conglomerate and second, an analysis of the distances from the center of the cluster/conglomerate will allow the grouping of similar zones. Once we have done the different tests, we will analyze the results obtained for 4 clusters. The final cluster centers are computed as the mean for each variable within each final cluster. The final cluster centres reflect the characteristics of the typical case for each cluster. These new clusters are:

Cluster 1. Sector: Area gasometri. Cluster 2. Sectors: Stefano Siccoli; Colico; Bellagio; Luigi Mercantini; Bovisasca; Don Giuseppe Andreoli; Filippo Baldinucci; Giuseppe Candiani; Antonio Carnevali; Cosenz; Morghen; Candiani; Piazzale Lugano; Arrivabene; Acerenza; Bernardo Davanzatti; Conte Verde; Livigno. Cluster 3. Sectors: Don Minzoni and Luigi Bodio. Cluster 4. Sectors: Raffaele Lambruschini; Giuseppe La Masa; Paolo Mariani; Bovisasca-Cosenz; Durando-Schiaffino.

\section{Modeling economical development, cultural recovery and green areas index}

Considering the variables from the previous models and adding the variable that determines the distance of the sector to the train station (the most important 
arrival point for the visitors) and the variable that determines the walking time from the train station to each sector, we will be indirectly introducing the possible financial development of all the sectors. Furthermore, we have developed the same multivariate analysis than the one explained at point 3 . This fact has led to the definition of a new index and a new classification of the zone.

\subsection{Index based on the first component}

From the factorial matrix (components matrix) and from the first main component we define index 2 for the ability of economical development as:

$$
I N D G_{2}=\sum_{i=1}^{16} a_{i 1} z_{i}
$$

$I N D G_{2}=0,023 Z_{1}+0,037 Z_{2}+0,032 Z_{3}+0,041 Z_{4}+0,059 Z_{5}+0,013 Z_{6}-0,176 Z_{7}+0,059 Z_{8}+$ $+0,103 Z_{9}-0,182 Z_{10}+0,174 Z_{11}+0,138 Z_{12}+0,212 Z_{13}+0,214 Z_{14}+0,045 Z_{15}+0,182 Z_{16}$

The values for each sector give us positive and negative values. We can make a transformation defined by the same function as (5). Listing the sectors in descendent order, the function takes the values represented in figure 2 :



Figure 2: Ability of economical development.

\subsection{Classification in homogeneous zones according to economical development, cultural recoverability and green areas}

In the same way as in point 3.7 , the factors obtained during the factorial analysis have been taken as four new variables. This will let us apply a cluster analysis or conglomerate analysis to the 27 areas linked to the factors that will classify the zones as homogeneous due to their belonging to the same cluster. The classification is different from the one previously obtained. This is a consequence of the introduction of distances and walking times from the main visitors' arrival point as a new variable. This can generate an improvement of the financial development possibilities: an asset to the greenery and cultural development. This new classification in 4 clusters is:

Cluster 1. Sector: area gasometri. Cluster 2. Sectors: Don Minzoni; Giuseppe Candiani; Luigi Bodio; Conte Verde; Livigno. Cluster 3. Sectors: Stefano Siccoli; Colico; Bellagio; Luigi Mercantini; Bovisasca; Don Giuseppe 
Andreoli; Filippo Baldinucci; Antonio Carnevali; Cosenz; Bellagio; Morghen; Candiani; Piazzale Lugano; Arrivabene; Acerenza; Bernardo Davanzatti. Cluster 4. Sector: Raffaele Lambruschini.

\section{Classification maps}

The following maps present the homogeneity analysis of the sectors grouped in clusters. For each cluster, the affinity of the elements and the future development will be similar. In the first map, the classification responds to the ability of green areas and cultural recovery and, in the second map, distances and walking-times for each section have been included introducing financial development factors in the first cluster analysis.

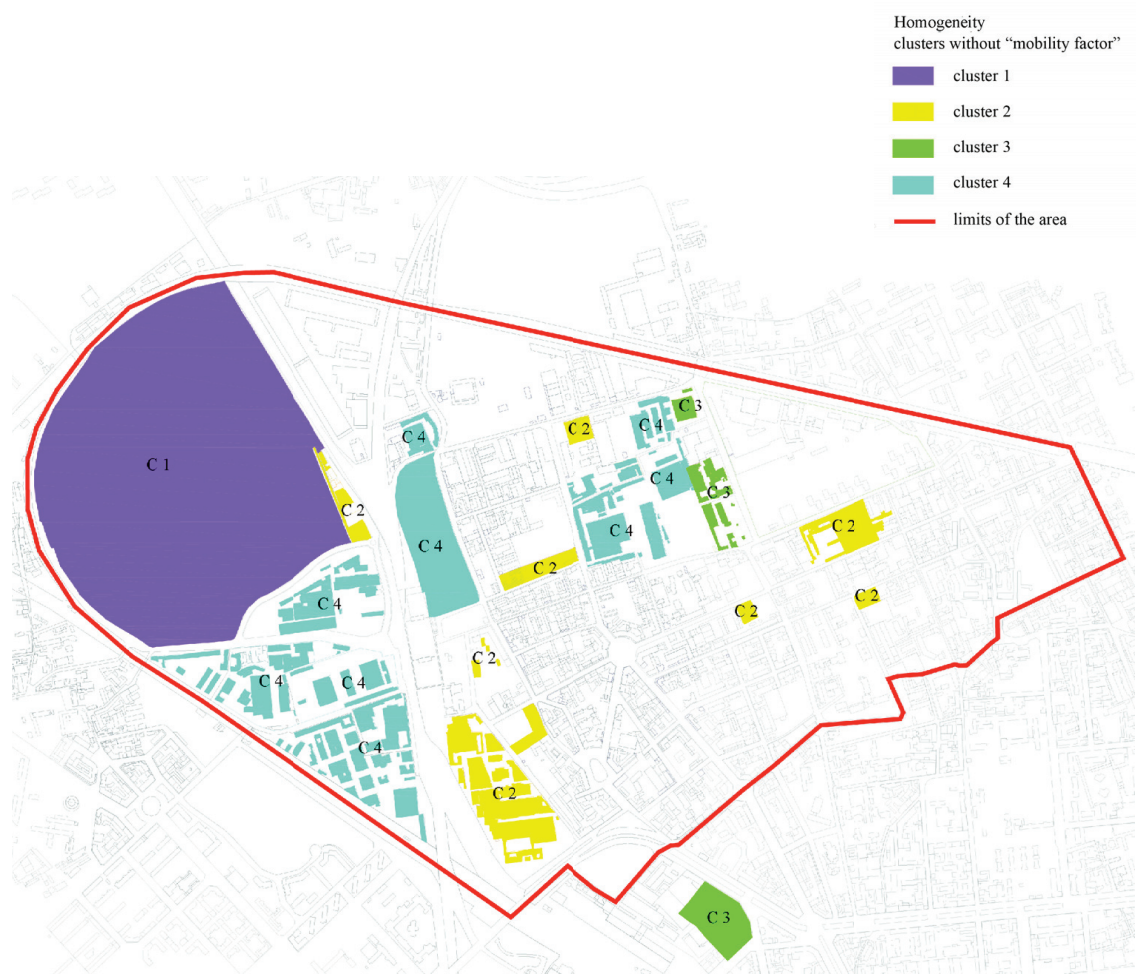

Figure 3: Homogeneity sectors without mobility factors. 


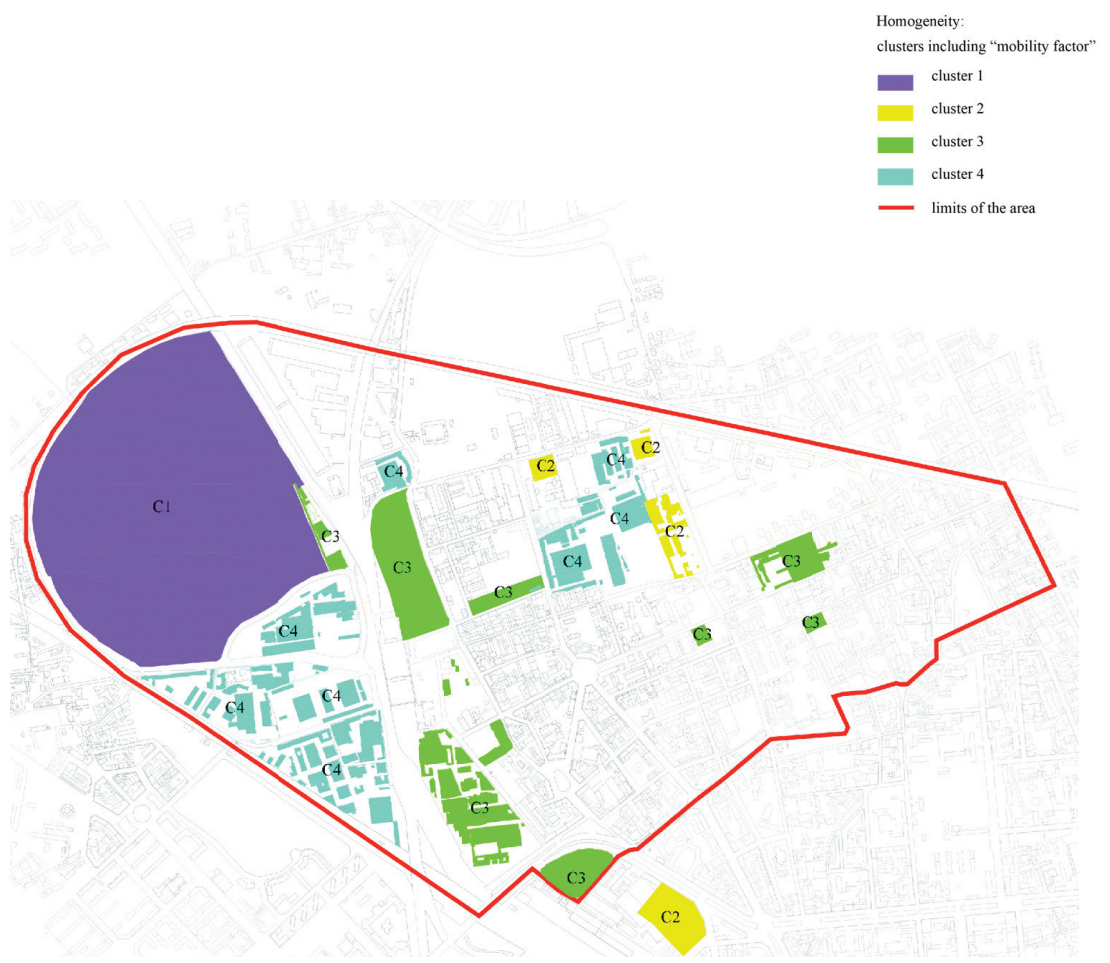

Figure 4: Homogeneity sectors with mobility factors.

\section{Conclusions}

Looking forward to a sustainable development of the area of Bovisa and the recovery of its industrial archaeology, an analysis has been developed to define the quality and quantity of the greenery, cultural life and industrial heritage of the whole area. The aim of this analysis is the planning of an intervention at four parallel levels: architectonical, urban, social and cultural that will lead to a sustainable gentrification process. Furthermore, a classification of the area of Bovisa in homogeneous zones there has been obtained according to their cultural and greenery recoverability. In order for this, a multivariate analysis has been applied to the data obtained after the quantification of the variables that influence those processes. Moreover, adding the variables that determine walking distances and time to the sectors from the main communications node of the area, a new classification has been developed to be compared to its previous one. In addition, diverse regression models have been created that will let us generate and study similar and future simulations. However, for further research, new variables must be considered that will reflect the influence of economical factors like the price of the land, possible investments in the public transport system, the costs of the 
purification of the soil, etc. This will lead to a description of each sector according to the needs and requirements of possible investors.

\section{References}

[1] Cognetti, Francesca. Bovisa in una goccia. Nuovi equilibri per un quartiere in trasformazione. Polipress, Politecnico di Milano, 1st Edition June, 2007.

[2] Sacramento, N. Zeiske, C. ARTocracy. Art, informal space and social consequence: a curatorial handbook in collaborative practice. Jovis Verlag $\mathrm{GmbH}$; Berlin, 2010.

[3] Janet M. Wagner; Daniel G. Shimshak. Stepwise selection of variables in data envelopment analysis: Procedures and managerial perspectives. European Journal of Operational Research 180; pp 57-67. 2007.

[4] Hair, J.F. Andreson, R.E. Tatham, R.L. Black, W.C. Análisis multivariante. Ed. Pearon/Prentice Hall. 2004.

[5] SPSS 9.0 Inc. Regression models. 1999.

[6] S-Plus 2000. Guide to statistics. Vol. 1, 2; Mathsoft, Inc. 1999.

[7] Celemín, J. P. El estudio de la Calidad de vida ambiental. Definiciones conceptuales. Elaboración de índices y su aplicación en la ciudad de Mar de Plata. Hologramática. - Facultad de Ciencias Sociales - UNLZ - Año IV, Número 7, V1, pp. 71-98. (2007) [On-line] www.hologramatica.com.ar; www.unlz.edu.ar/sociales/hologramatica

[8] I. García-Lautre; C. Gil-Canaleta; P. Pascual-Arzoz \& M. Rapún Gárate. Una propuesta metodológica para la ordenación de las infraestructuras regionales. Estudios Regionales No 51. Pp. 145-170. 1998

[9] Calsamiglia, X. (1990): "La financiación de las Comunidades Autónomas y el principio de solidaridad”. De Economía Pública, 6, pp. 3-43. 